\title{
Role of alveolar epithelial ICAM-1 in lipopolysaccharide-induced lung inflammation
}

\author{
B. Beck-Schimmer*,\#, C. Madjdpour*,\#, S. Kneller*,\#, U. Ziegler", T. Pasch*, R.P. Wüthrich", \\ P.A. Ward ${ }^{+}$, R.C. Schimmer
}

Role of alveolar epithelial ICAM-1 in lipopolysaccharide-induced lung inflammation. B. Beck-Schimmer, C. Madjdpour, S. Kneller, U. Ziegler, T. Pasch, R.P. Wüthrich, P.A. Ward, R. C. Schimmer. (C) ERS Journals Ltd 2002.

ABSTRACT: Intercellular adhesion molecule-1 (ICAM-1) is known to play a central role in lung inflammation. Limited information, however, is available regarding the expression and biological function of ICAM-1 in the alveolar epithelial compartment. The current report analyses the expression pattern of ICAM-1 in primary cultures of rat alveolar epithelial cells (AECs) and in the rat lung following instillation of bacterial endotoxin (lipopolysaccharide (LPS)) in order to better define the role of alveolar epithelial ICAM-1.

AECs stimulated in vitro with LPS were evaluated for ICAM-1 and ICAM-1 messenger ribonucleic acid content. Adherence assays with neutrophils and macrophages were performed. Endotoxin-induced ICAM-1 upregulation on AECs was demonstrated in vivo by immunofluorescence staining. In addition, the effect of intratracheally-instilled anti-ICAM-1 was assessed.

Significant upregulation of ICAM-1 occurred in vitro and in vivo on AECs after LPS stimulation. Adherence assays showed a $114 \%$ increase in adhesion of neutrophils to AECs. Antibody directed against ICAM-1 reduced this adhesion by $40 \%$. A significant reduction in the number of neutrophils in bronchoalveolar lavage fluid and whole lung was seen under airway ICAM-1 blockade.

These data indicate that intercellular adhesion molecule-1 participates in the inflammatory response to lipopolysaccharide-induced lung injury in the distal airways by interacting mainly with neutrophils.

Eur Respir J 2002; 19: 1142-1150.

\begin{abstract}
*Institute of Anaesthesiology, University of Zurich Medical School, Institutes of "Physiology and Anatomy, University of Zurich, Zurich and ${ }^{\S}$ Dept of Orthopaedic Surgery, University of Basel, Basel, Switzerland, ${ }^{+}$Dept of Pathology, University of Michigan Medical School, Ann Arbor, MI, USA.
\end{abstract}

Correspondence: B. Beck-Schimmer, Institutes of Physiology and Anesthesiology, University of Zurich-Irchel, Winterthurerstrasse $190, \quad \mathrm{CH}-8057$ Zurich, Switzerland.

Fax: 4116356814

E-mail: bbeck@physiol.unizh.ch

Keywords: Adhesion molecule, leukocytes, lipopolysaccharide, lung inflammation, respiratory epithelial cells

Received: April 192001

Accepted after revision November 20 2001

This study was supported by the Swiss National Science Foundation grant No. 31-55702.98, the Hartmann-Müller Foundation, Switzerland, and the Bonizzi-Theler Foundation, Switzerland.
Recent studies have identified requirements for adhesion molecules and leukocytes in the lung vascular compartment in several models of acute lung injury [1-3]. Leukocytes homing to sites of acute inflammation is a crucial step during an inflammatory response. Adhesion molecules, such as intercellular adhesion molecule-1 (ICAM-1), play a major part in this process by mediating adherence of leukocytes to endothelium and initiating extravasation of these cells [4]. ICAM-1, a member of the immunoglobulin superfamily, is a cell surface glycoprotein and a ligand for the $\beta_{2}$ integrins CD11a/CD18 (leukocyte functionassociated antigen-1) and CD11b/CD18 (Mac-1). In the vascular compartment, $\beta_{2}$ integrin molecules reacting with endothelial cell "counter-receptors", such as ICAM-1, mediate firm adhesion of the leukocytes to the endothelium [5]. Epithelial ICAM1, however, has been characterized much less and its functional role might be different from that of endothelial ICAM-1. Previous studies hypothesized that in cases of inflammatory response, leukocytes from the extravascular space penetrate through the alveolar epithelial barrier and reach the alveolar space, where they interact with alveolar epithelial cells (AECs) [6]. Furthermore, it is known that polymorphonuclear cells (PMNs) can impair the integrity of endothelial cells and even kill microvascular endothelial cells [7]. One of the goals of the present work was, therefore, to investigate the eventual effect of PMNs on respiratory epithelial cells.

Distal airway epithelial cells are vital for maintenance of the pulmonary air/blood barrier. Gaseous diffusion occurs across alveolar type I cells, large thin cells that cover the majority of the alveolar surface. Type II cells, however, are cuboidal cells that produce pulmonary surfactant. They are also progenitor cells, proliferating and differentiating into type I cells [8]. AECs are known to play a major role in the regulation of immune responses in the lung $[9,10]$. Although it is known that ICAM-1 is expressed on AECs, the exact role of epithelial expression in lipopolysaccharide (LPS)-induced lung injury has not been demonstrated to date.

In the present study, the in vitro and in vivo 
expression of the adhesion molecule ICAM-1 on AECs was evaluated and their functional implications assessed.

The results of this study must be interpreted with the understanding that in vitro and in vivo animal studies of LPS-induced lung injury are experimental systems, which might not fully reproduce clinical situations. However, investigations using this and similar models have enormously advanced the understanding of inflammation and will provide further insight into the immunopathology underlying human septic situations.

\section{Material and methods}

\section{Material}

Except where noted, all reagents were purchased from Sigma (Buchs, Switzerland).

\section{Animals}

Pathogen-free male Long-Evans rats (250-300 g) were purchased from M \& B, Ry, Denmark. Rats were anaesthetized with subcutaneously adminis-

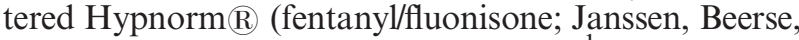
Belgium) $0.25 \mathrm{~mL} \cdot \mathrm{kg}$ body weight ${ }^{-1}$, Domitor $\mathbb{R}$ (medetomidine; Pfizer, Inc., Westchester, PA, USA) $0.25 \mathrm{~mL} \cdot \mathrm{kg}$ body weight ${ }^{-1}$ and $0.1 \%$ atropine $0.05 \mathrm{~mL}$. $\mathrm{kg}$ body weight ${ }^{-1}$. All animal experiments and animal care were approved by the Swiss Veterinary Health Authorities.

\section{Isolation and culture of alveolar epithelial cells}

AECs from rat lungs were collected following previously described protocols [11, 12]. Cells were grown to confluence over a 3-day period. Purity was assessed using a fluorescein-labelled lectin, Griffonia simplicifolia I (macrophage staining).

\section{Stimulation with lipopolysaccharide and cytokines}

Confluent AECs were stimulated overnight with various agents: LPS (Escherichia coli, serotype 055:B5) at $100 \mu \mathrm{g} \cdot \mathrm{mL}^{-1}$, recombinant mouse tumour necrosis factor- $\alpha(\mathrm{TNF}-\alpha)$ at $20 \mathrm{ng} \cdot \mathrm{mL}^{-1}$ and interferon gamma $(\mathrm{IFN}-\gamma)$ at $500 \mathrm{U} \cdot \mathrm{mL}^{-1}$. Prior to cell stimulation, the medium was changed to Dulbecco modified Eagle medium (DMEM) $/ 1 \%$ foetal bovine serum (FBS).

\section{Northern blot for intercellular adhesion molecule-1}

Ribonucleic acid (RNA) was extracted from confluent monolayers of unstimulated (control) and

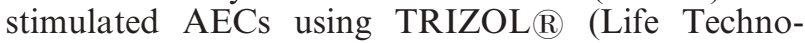
logies, Basel, Switzerland), chloroform (Fluka, Buchs, Switzerland) and isopropanol (Fluka). The RNA $(5 \mu \mathrm{g})$ was loaded on to a $1 \%$ agarose/formaldehyde gel. After electrophoresis, the RNA was transferred to a nylon Zeta-Probe $(\mathrm{R})$ blotting membrane (BioRad, Hercules, CA, USA). Equal loading was confirmed by rehybridization with $\beta$-actin. The RNA was crosslinked using an ultraviolet filter and the blots were prehybridized for $30 \mathrm{~min}$. Hybridization was performed overnight with a ${ }^{32} \mathrm{P}$-labelled probe using a random priming method (Life Technologies). The blots were exposed to XAR5 Kodak film at $-70^{\circ} \mathrm{C}$.

Enzyme-linked immunosorbent assay for intercellular adhesion molecule-1 expression

To determine ICAM-1 expression on the surface of AECs, a cell-based enzyme-linked immunosorbent assay (ELISA) was performed according to a previous protocol [13]. Final optical density (OD) at $492 \mathrm{~nm}$ was calculated by subtracting the OD of cells incubated with the secondary antibody alone or with a control antibody (mineral oil-induced plasmocytoma cell (MOPC) 21, mouse immunoglobulin-G (IgG)) (Pharmingen, San Diego, CA, USA) from the OD of cells incubated with primary and secondary antibody together.

\section{Preparation of neutrophils}

Whole blood was obtained from healthy human volunteers and neutrophils were isolated as described previously $[13,14]$. Neutrophils were pre-incubated with blocking antibodies to FcRII (mouse antihuman CD32) and FcRIII (mouse antihuman CD16, Pharmingen) $\left(10 \mu \mathrm{g} \cdot \mathrm{mL}^{-1}\right)$ at $37^{\circ} \mathrm{C}$ for $15 \mathrm{~min}$, washed and added to the wells.

\section{Assay of neutrophil adherence to alveolar epithelial cells}

AECs were added to 96 -well plates at a density of $5 \times 10^{4}$ cells $\cdot$ well $^{-1}$ and grown to confluence at $37^{\circ} \mathrm{C}$ in $5 \%$ carbon dioxide. Cells were stimulated with $100 \mu \mathrm{g} \cdot \mathrm{mL}^{-1}$ LPS overnight, washed six times and then incubated with monoclonal mouse anti-ICAM-1 $\left(10 \mu \mathrm{g} \cdot \mathrm{mL}^{-1}, 1 \mathrm{~A} 29\right.$; Serotec, Oxford, UK) or control antibody $\left(10 \mu \mathrm{g} \cdot \mathrm{mL}^{-1}\right.$, MOPC-21) at $37^{\circ} \mathrm{C}$ in $5 \% \mathrm{CO}_{2}$ for $20 \mathrm{~min}$. After washing the cells once with DMEM/ $10 \%$ FBS, $1 \times 10^{5}$ neutrophils, previously incubated with FcRII and FcRIII, were added to each well and incubated at $37^{\circ} \mathrm{C}$ in $5 \% \mathrm{CO}_{2}$ for $30 \mathrm{~min}$. Nonadherent cells were removed by washing each well four times with culture medium. The remaining neutrophils were counted immediately using a cell chamber.

\section{Alveolar macrophages: isolation, preparation and adherence to alveolar epithelial cells}

Rat alveolar macrophages were harvested as described previously [15]. Unstimulated and stimulated AECs were incubated with anti-ICAM-1 (1A29) or control antibody (MOPC-21) at a concentration of $10 \mu \mathrm{g} \cdot \mathrm{mL}^{-1}$ at $37^{\circ} \mathrm{C}$ for $20 \mathrm{~min}$. Macrophages were preincubated with blocking antibodies to FcRII and 
FcRIII, as described above. AECs were washed and incubated with macrophages at $37^{\circ} \mathrm{C}$ in $5 \% \mathrm{CO}_{2}$ for $30 \mathrm{~min}$. Nonadherent cells were washed away and adherent cells were counted.

\section{Cytotoxicity assay}

Cytotoxicity was measured using a standard lactate dehydrogenase (LDH) assay (Promega, Madison, WI, USA). AECs were seeded into the wells of a 96-well culture dish, as described above. Cells were stimulated with $100 \mu \mathrm{g} \cdot \mathrm{mL}^{-1}$ LPS overnight. Neutrophils $\left(1 \times 10^{6}\right)$ in phosphate-buffered saline (PBS; $\mathrm{pH} 7.4) / 0.02 \%$ bovine serum albumin (BSA) were added to each well. The neutrophils were allowed to settle on to the epithelial cell monolayer for $30 \mathrm{~min}$ before being stimulated with phorbol 12-myristate 13-acetate (PMA) $\left(100 \mathrm{ng} \cdot \mathrm{well}^{-1}\right)$. After incubation for $2 \mathrm{~h}$, the supernatant was removed from each well and centrifuged at $700 \times g$ for $5 \mathrm{~min}$. Some AECs were incubated with lysing solution (from assay kit) for 45 min (target cell maximum LDH release). Supernatant was also collected from wells of AECs that had not been incubated with neutrophils (spontaneous LDH release). Cytotoxicity was calculated according to the following formula:

$$
\text { Cytotoxicity }(\%)=\frac{\mathrm{ER}-\mathrm{SR}}{\mathrm{TR}-\mathrm{SR}} \times 100
$$

where ER is experimental release, $\mathrm{SR}$ is spontaneous release, and TR is total release.

\section{Fluorescence staining for intercellular adhesion molecule-1 in lipopolysaccharide-injured lungs}

LPS resuspended in PBS or PBS alone (control animals) was applied intratracheally, as described previously [16]. After $6 \mathrm{~h}$, rat lungs were frozen in liquid nitrogen. Dual staining was performed with anti-ICAM-1 and a monoclonal goat antimouse vascular endothelial (VE) cadherin (Santa Cruz Biotechnology, Santa Cruz, CA, USA). Sections were incubated with control antibody or with the secondary antibody alone. All antibodies were diluted in $\mathrm{PBS} / 1 \%$ BSA. Slides were fixed with $3 \%$ paraformaldehyde (PFA), blocked with PBS/10\% FBS and incubated overnight with anti-VE cadherin at a concentration of $10 \mu \mathrm{g} \cdot \mathrm{mL}^{-1}$ in $\mathrm{PBS} / 1 \% \mathrm{BSA} / 0.3 \%$ Triton X-100 at $4{ }^{\circ} \mathrm{C}$. Incubation with a flurorescein isothiocyante (FITC)-labelled secondary rabbit antigoat IgG followed. Slides were then fixed with 3\% formalin, which was followed by ICAM-1 staining. Mouse antirat ICAM-1 was diluted to $1 \mu \mathrm{g} \cdot \mathrm{mL}^{-1}$ and incubated with the slides at $4{ }^{\circ} \mathrm{C}$ for $1 \mathrm{~h}$. Staining with a secondary Cy3-goat antimouse IgG conjugate (1:500, Jackson Immunoresearch Laboratories, Inc., West Grove, PA, USA) was performed. Finally, sections were covered with mounting medium (DAKO Corporation, Carpinteria, CA, USA) containing 1,4diazabicyclo[2.2.2]octane. Immunofluorescence staining was examined using a confocal laser scanning microscope (Zeiss, Jena, Germany).
A second dual staining was performed with antiICAM-1 and a type II cell antibody directed against the type $\mathrm{IIb}$ sodium phosphate $(\mathrm{NaPi})$ cotransporter, which is exclusively found in the apical membrane of type II cells of the alveolar epithelium [17]. Sections were first incubated with anti-ICAM-1 and the secondary Cy3-labelled antibody as described above. Sections were then fixed with $3 \%$ PFA and incubated overnight with anti-NaPi-IIb antiserum (diluted $1: 500$ in $\mathrm{PBS} / 1 \% \mathrm{BSA} / 0.3 \%$ Triton $\mathrm{X}-100$ ) at $4{ }^{\circ} \mathrm{C}$. A secondary FITC-labelled pig antirabbit antibody (DAKO Corporation) was added. The final steps were the same as described above.

In vivo blocking studies with intercellular adhesion molecule-1 antibody

Rats were anaesthetized as described above. LPS $(150 \mu \mathrm{g})$, together with $200 \mu \mathrm{g}$ polyclonal rabbit antirat ICAM-1, was instilled intratracheally in $300 \mu \mathrm{L}$ PBS [18]. IgG was used as a control. Bronchoalveolar lavage (BAL) was performed and cells were counted and stained with Diff Quick (Dade Behring, Duedingen, Switzerland) after $4 \mathrm{~h}$ of injury. Lungs were homogenized and myeloperoxidase (MPO) levels were determined after $240 \mathrm{~s}$, as previously described [19].

\section{Lactate dehydrogenase release}

In order to evaluate the toxicity of the cytokine and LPS concentrations employed, LDH levels in the supernatants of stimulated and unstimulated cells were measured using a nonradioactive assay system (Promega).

\section{Statistical analysis}

All experiments were performed at least three times. Three different sets of ELISAs were analysed. Analysis of variance (ANOVA) with post-ANOVA comparison was performed to assess the significance of differences. A p-value of $<0.05$ was considered significant. All values are expressed as mean \pm SEM.

\section{Results}

\section{Characterization of alveolar epithelial cells}

Monolayers of AECs were stained to detect macrophages. There was $<5 \%$ contamination. If the cultures were $<95 \%$ pure, they were not used for further experiments.

Upregulation of rat intercellular adhesion molecule-1 and its messenger ribonucleic acid in stimulated alveolar epithelial cells

In order to define the expression pattern of ICAM-1 under different stimulation conditions, AECs were 
exposed overnight to several agonists, including LPS $\left(100 \mu \mathrm{g} \cdot \mathrm{mL}^{-1}\right)$, recombinant mouse TNF- $\alpha\left(20 \mathrm{ng} \cdot \mathrm{mL}^{-1}\right)$ and recombinant rat IFN- $\gamma\left(500 \mathrm{U} \cdot \mathrm{mL}^{-1}\right) . \mathrm{LDH}$ assays demonstrated all the concentrations described above to be nontoxic (data not presented). The relatively high concentration of LPS was chosen in accordance with the in vivo assay and pre-existing data [13]. In addition, concentration-dependent ICAM-1 expression revealed the same results with 10 and $100 \mu \mathrm{g} \cdot \mathrm{mL}^{-1}$ LPS stimulation. Figure 1a shows upregulation of ICAM-1 in AEC primary culture $24 \mathrm{~h}$ after stimulation with any of the three agonists. LPS enhanced ICAM-1 expression by $39 \%$, TNF- $\alpha$ by $21 \%$ and IFN- $\gamma$ by $13 \%$. ICAM-1 expression on stimulated cells was significantly increased compared to expression on control cells $(\mathrm{p}<0.01)$. At the messenger RNA (mRNA) level there was a similar result, with the most prominent upregulation of ICAM-1 occurring under LPS stimulation, as assessed by Northern blot (fig. 1b).

Time course of upregulation of rat intercellular adhesion molecule-1 and its messenger ribonucleic acid in stimulated alveolar epithelial cells

A time course was established for upregulation of ICAM-1 and ICAM-1 mRNA in primary cultures of AECs stimulated with LPS. Cells were incubated for 2, 4, 6, 8 and $24 \mathrm{~h}$ with LPS $\left(100 \mu \mathrm{g} \cdot \mathrm{mL}^{-1}\right)$ and a cell-based ELISA for ICAM-1 was performed. Control cells were exposed to PBS instead of LPS. Maximal expression of ICAM-1 occurred after $6 \mathrm{~h}$ $(36 \%$ increase; $\mathrm{p}<0.01)$ (fig. 2a). Upregulation of ICAM-1 mRNA is shown in figure $2 \mathrm{~b}$. Early expression started after $2 \mathrm{~h}$ with sustained expression for $\leqslant 24 \mathrm{~h}$. A relatively high baseline expression of ICAM-1 was found. This finding is in contrast with the result with L2 cells, where there was only slight expression in unstimulated cells [13].

As only a $40 \%$ increase in cell surface ICAM-1 expression was seen after LPS stimulation, compared to the significant increase in ICAM-1 mRNA levels, soluble ICAM-1 concentrations in the media were measured by Western blot. Interestingly, there was no difference between ICAM-1 concentrations in the supernatant from control cells and LPS-stimulated cells.

Adherence of neutrophils and alveolar macrophages to alveolar epithelial cells

In order to evaluate the biological implications of ICAM-1 expression on AECs, adherence assays were performed with neutrophils and alveolar macrophages. Neutrophil adherence to unstimulated AECs was appreciable (35 adherent cells $\cdot$ square $^{-1}$ ) (fig. 3). Compared to unstimulated AECs, the adherence of neutrophils to LPS-stimulated AECs increased by $114 \%$ (75 adherent cells $\cdot$ square $\left.^{-1}\right)$. Neutrophil adherence to stimulated AECs decreased by $40 \%(p<0.001)$ in the presence of blocking antibodies to ICAM-1. At the beginning of the experiment, different antibody

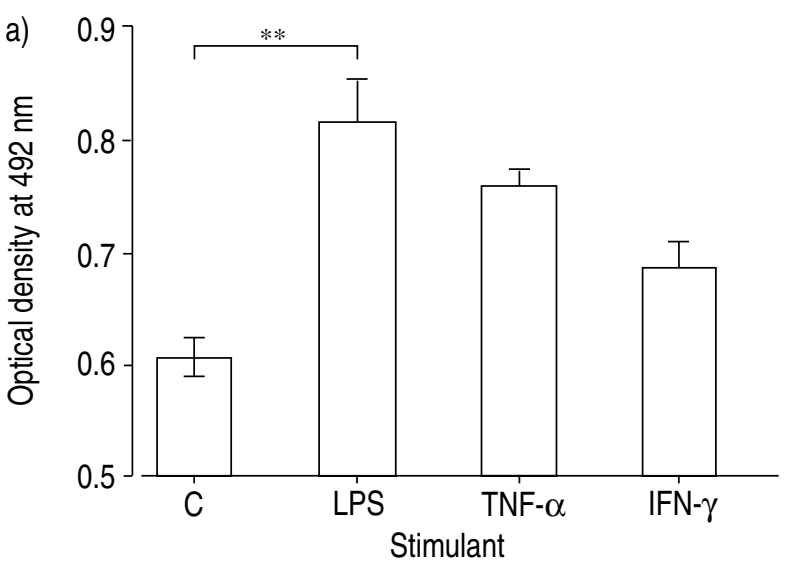

b)

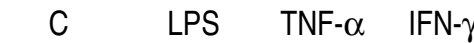

ICAM-1

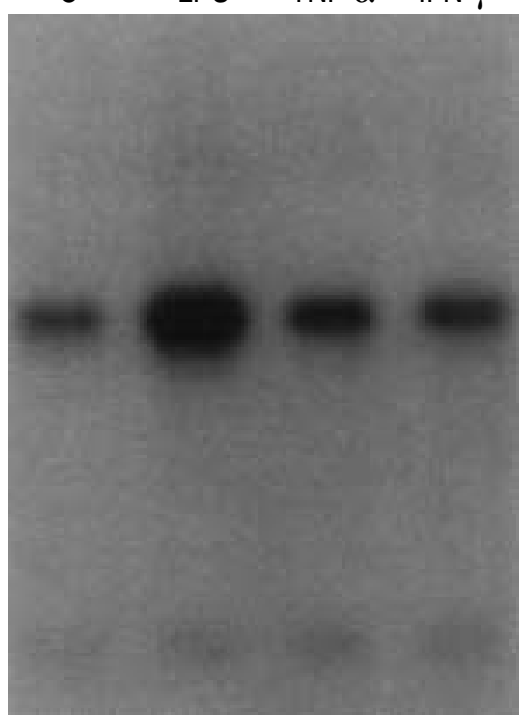

c)

$\beta$-actin $\longrightarrow$

Fig. 1.- Upregulation of a) rat intercellular adhesion molecule-1 (ICAM-1) protein and b) ICAM-1 messenger ribonucleic acid (mRNA) in alveolar epithelial cells. Cells were unstimulated (control (C)) or stimulated with lipopolysaccharide (LPS; $100 \mu \mathrm{g} \cdot \mathrm{mL}^{-1}$ ), recombinant mouse tumour necrosis factor- $\alpha$ (TNF- $\alpha ; 20 \mathrm{ng} \cdot \mathrm{mL}^{-1}$ ) or recombinant rat interferon- $\gamma\left(\right.$ IFN- $\gamma ; 500 \mathrm{U} \cdot \mathrm{mL}^{-1}$ ) for $24 \mathrm{~h}$. a) ICAM-1 measured by enzyme-linked immunosorbent assay (ELISA). Three ELISAs were evaluated. Data are expressed as mean \pm SEM. b, c) Northern blot $(5 \mu \mathrm{g}$ ribonucleic acid). Equal loading was shown by rehybridization with $\beta$-actin (c). All stimulated cells showed increased ICAM-1 mRNA levels, with LPS being the most potent agent. **: $\mathrm{p}<0.01$ versus control. 


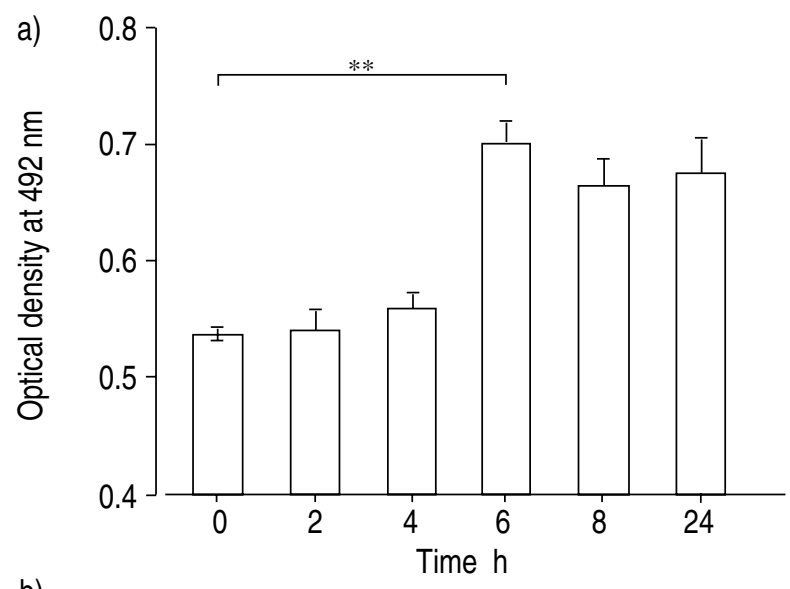

b)

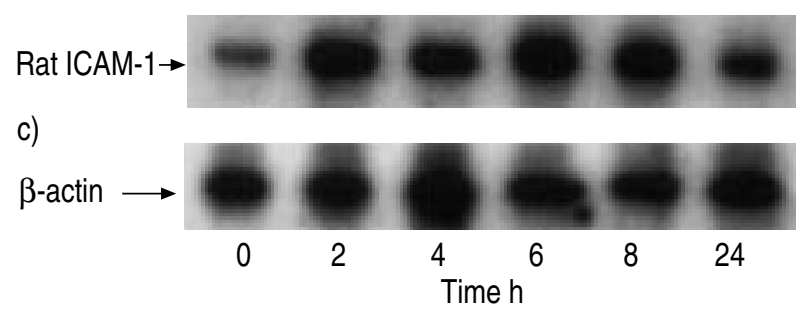

Fig. 2.-Time course of upregulation of a) intercellular adhesion molecule-1 (ICAM-1) protein and b) ICAM-1 messenger ribonucleic acid (mRNA) in alveolar epithelial cells incubated with LPS. a) ICAM-1 measured by enzyme-linked immunosorbent assay (ELISA). Three ELISAs were evaluated. A 36\% increase in ICAM-1 was seen after 6 h. Data are expressed as mean \pm SEM. b, c) Northern blot $(5 \mu \mathrm{g}$ ribonucleic acid). Equal loading was shown by rehybridization with $\beta$-actin (c). Maximal expression of ICAM-1 mRNA occurred within 2 h. ${ }^{* *}$ : $\mathrm{p}<0.01$ versus time 0 (control).

concentrations in the range $5-100 \mu \mathrm{g} \cdot \mathrm{mL}^{-1}$ were evaluated, with $10 \mu \mathrm{g} \cdot \mathrm{mL}^{-1}$ being the most efficient concentration concerning blockade.

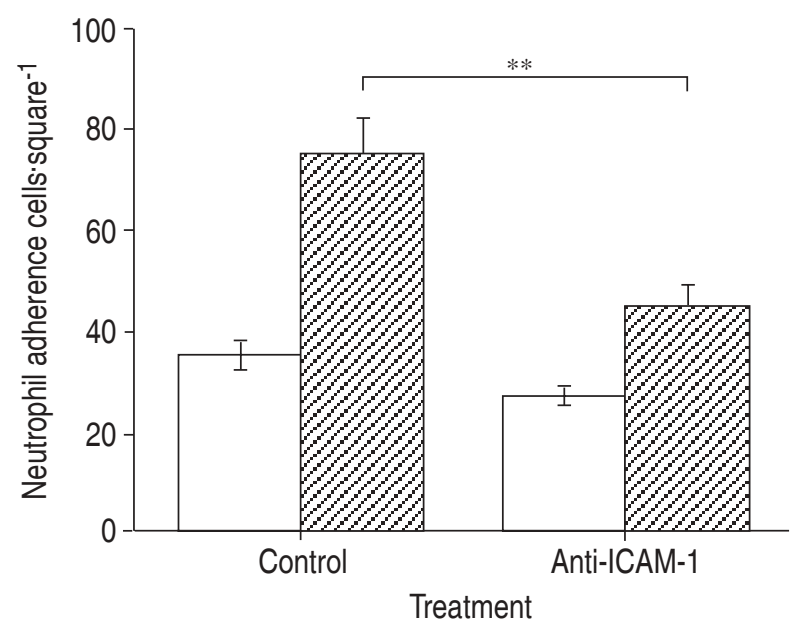

Fig. 3.-Adherence of neutrophils to alveolar epithelial cells (AECs) unstimulated (control; $\square$ ) or stimulated (Z) overnight with lipopolysaccharide (LPS; $100 \mu \mathrm{g} \cdot \mathrm{mL}^{-1}$ ). Blocking intercellular adhesion molecule-1 (ICAM-1) with monoclonal mouse antirat ICAM-1 $\left(1 \mathrm{~A} 29 ; 10 \mu \mathrm{g} \cdot \mathrm{mL}^{-1}\right)$ resulted in decreased adherence of neutrophils to AECs compared to control antibody ( $40 \%$ less on stimulated cells). The results of three single assays were analysed. Data are expressed as mean \pm SEM. ${ }^{* *}: \mathrm{p}<0.001$.

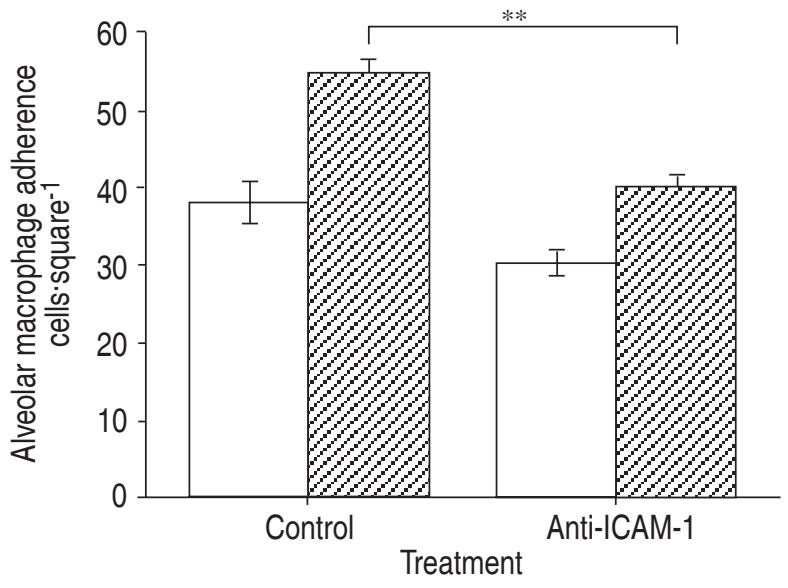

Fig. 4.-Adherence of alveolar macrophages to alveolar epithelial cells (AECs) unstimulated (control; $\square$ ) or stimulated $(\mathbb{Z})$ overnight with lipopolysaccharide (LPS; $100 \mu \mathrm{g} \cdot \mathrm{mL}^{-1}$ ). A modest decrease in adherence of macrophages to stimulated AECs $(28 \%)$ occurred in the presence of anti-intercellular adhesion molecule-1 (ICAM-1). The results of three single assays were analysed. Data are expressed as mean \pm SEM. $* *: \mathrm{p}<0.001$.

Similar adherence assays were performed with rat alveolar macrophages obtained from normal rat lungs by BAL. Adherence to nonstimulated AECs was 38 cells $\cdot$ square $^{-1}$, increasing to 55 cells $\cdot$ square $^{-1}$ in LPS-stimulated AECs (45\% increase). Blocking of ICAM-1 on the surface of AECs before incubation with macrophages resulted in a decrease in adhesion to stimulated AECs by $28 \%(\mathrm{p}<0.001)$ (fig. 4$)$.

\section{Damage to alveolar epithelial cells caused by neutrophils}

The ability of neutrophils to damage AECs was examined. PMA-stimulated neutrophils were incubated with LPS-stimulated AECs or with control cells for $2 \mathrm{~h}$. Figure 5 shows LDH release as an indirect measure of cell death. Neutrophils as a source of

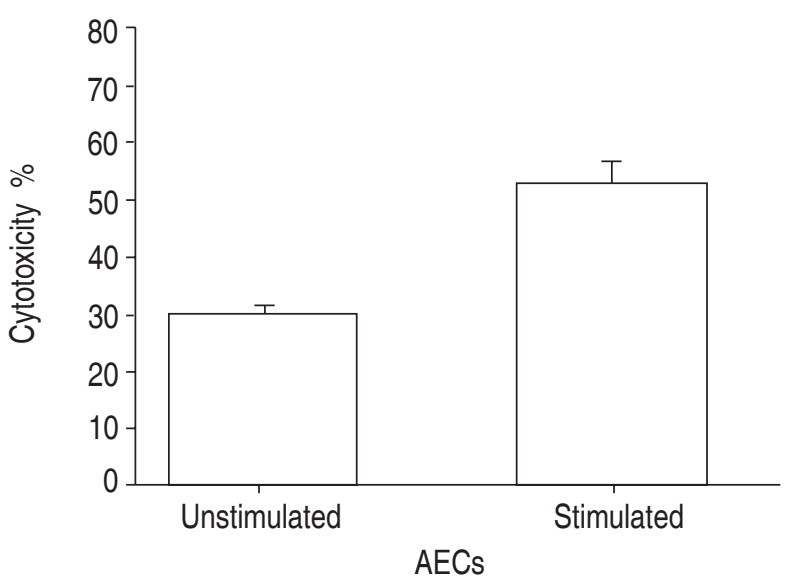

Fig. 5.-Alveolar epithelial cell (AEC) killing by phorbol 12myristate 13 -acetate (PMA)-stimulated neutrophils $\left(100 \mathrm{ng} \cdot \mathrm{we}^{1 l^{-1}}\right)$. AECs were unstimulated (control) or stimulated overnight with lipopolysaccharide (LPS; $100 \mu \mathrm{g} \cdot \mathrm{mL}^{-1}$ ) and then incubated with PMA-stimulated neutrophils for $2 \mathrm{~h}$. Data are expressed as mean \pm SEM. The experiment was carried out three times with similar results. $\mathrm{p}<0.005$. 
possible LDH release could be excluded by trypan blue staining, which showed them to be intact. Control AECs exposed to stimulated neutrophils showed a cytotoxicity of $30 \%$, whereas that of LPSstimulated AECs increased to $54 \%(\mathrm{p}<0.005)$.

In vivo upregulation of rat intercellular adhesion molecule-1 in lungs after stimulation with lipopolysaccharide

In order to study upregulation of airway ICAM-1 by LPS in vivo, sections of LPS- or PBS-treated lungs were used for immunostaining to assess ICAM-1 content. Costaining with VE cadherin and ICAM-1 showed clear ICAM-1 expression on endothelial cells in control lungs (fig. 6a). The pattern in LPS-stimulated lungs was similar, but with a clear increase in nonendothelially localized ICAM-1 (fig. 6b).

In addition, type II cell staining was performed to evaluate ICAM-1 expression on type I and type II cells. Interestingly, there was no ICAM-1 expression on type II cells in control animals (fig. 6c) or LPSstimulated animals (fig. 6d).
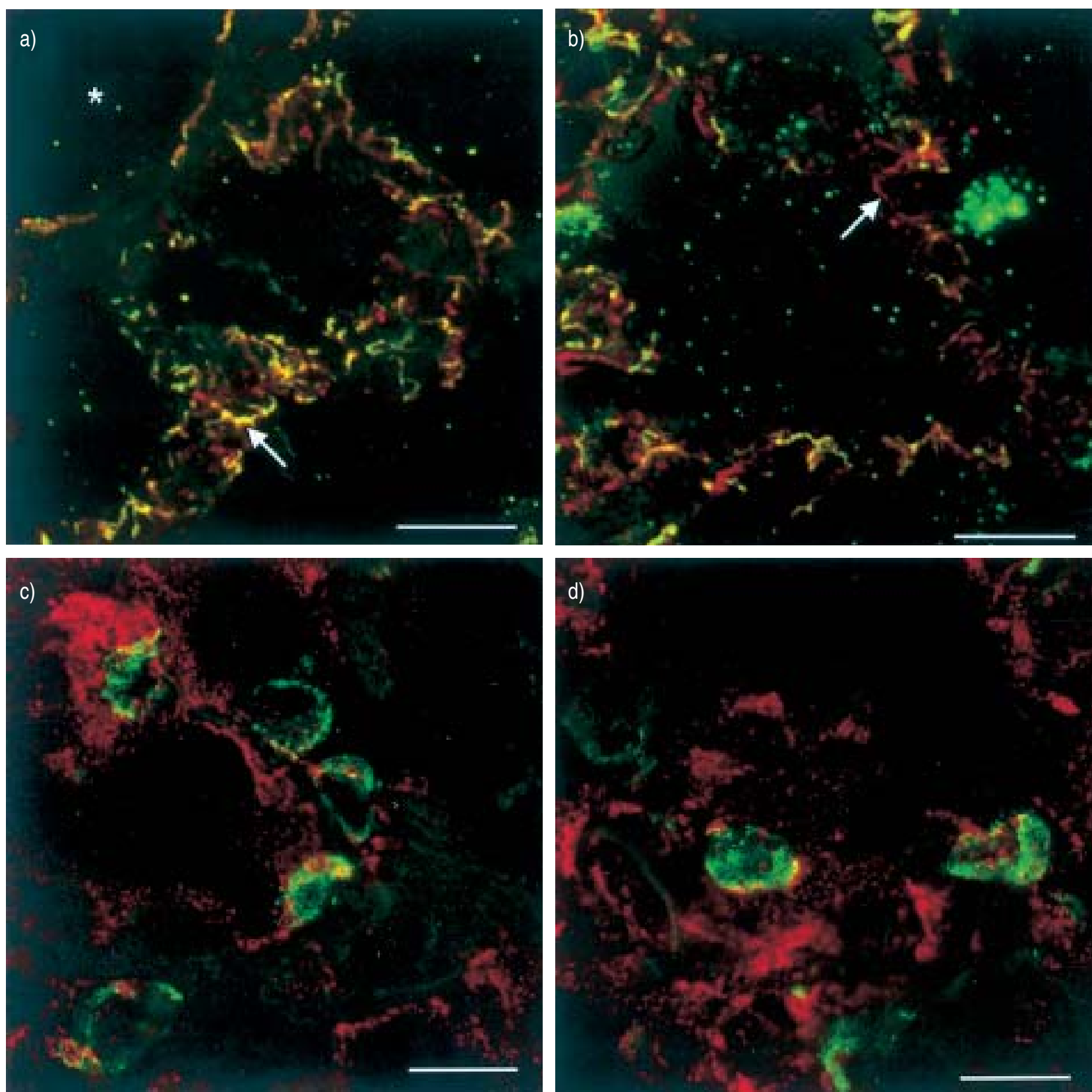

Fig. 6. - Immunofluorescence staining of intercellular adhesion molecule-1 (ICAM-1) in rat lung after harvesting $6 \mathrm{~h}$ after intratracheal instillation of: a, c) phosphate-buffered saline (PBS); and b, d) lipopolysaccharide (LPS). Frozen sections were immunostained for ICAM-1 (red) and vascular endothelial (VE)-cadherin (green; $a$ and b) or the type IIb sodium phosphate cotransporter (green; c and d). a) The yellow/orange colour represents double staining for ICAM-1 and VE-cadherin (arrow). The asterisk indicates a vessel lumen with yellow/ orange vascular endothelial lining. b) The red lined area (arrow) shows epithelial ICAM-1. Internal scale bars=a, b) $20 \mu \mathrm{m}$ and c, d) $10 \mu \mathrm{m}$. 


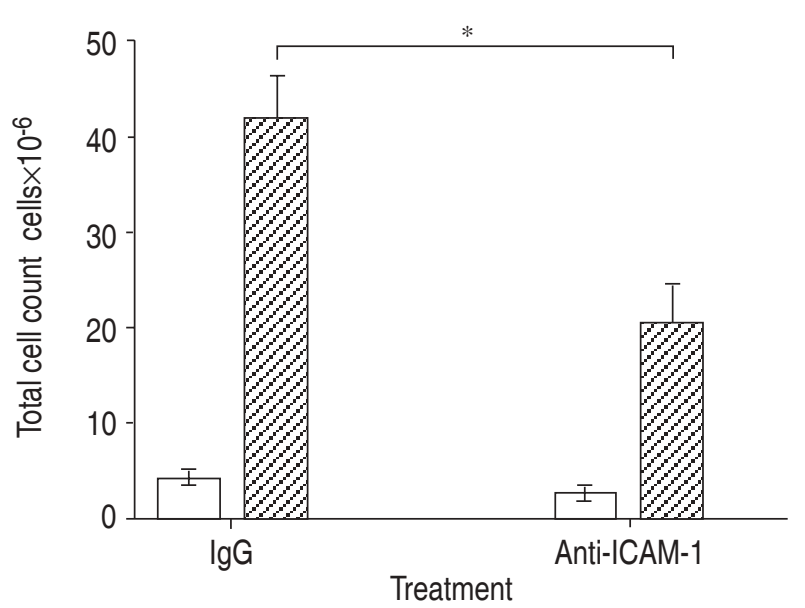

Fig. 7. - Total cell count in bronchoalveolar lavage fluid from rat lung after intratracheal intercellular adhesion molecule-1 (ICAM1) blockade in the lipopolysaccharide (LPS)-injured lung. Lungs were instilled with phosphate-buffered saline (PBS; $\square$ ) or LPS (ש্Z) in the presence of immunoglobulin-G (IgG) or anti-ICAM-1 $\left(200 \mu \mathrm{g} \cdot \mathrm{mL}^{-1}\right)$. The vascular system of the lungs was flushed $4 \mathrm{~h}$ later and the bronchoalveolar system lavaged four times with cold PBS. Blocking airway ICAM-1 reduced the cell count by $50 \%$ in bronchoalveolar lavage fluid. Data are expressed as mean \pm SEM $(\mathrm{n}=5) .{ }^{*}: \mathrm{p}<0.05$.

\section{Airway blocking of intercellular adhesion molecule-1}

Airway ICAM-1 was blocked using a polyclonal antibody [18]. Of the BAL fluid cells analysed with Diff Quick, 95\% were neutrophils and 5\% macrophages. After ICAM-1 blockade, the total BAL fluid cell content was reduced by $50 \%(\mathrm{p}<0.05)$ (fig. 7), whereas MPO levels were reduced by $35 \%(\mathrm{p}<0.01)$ compared to controls (fig. 8).

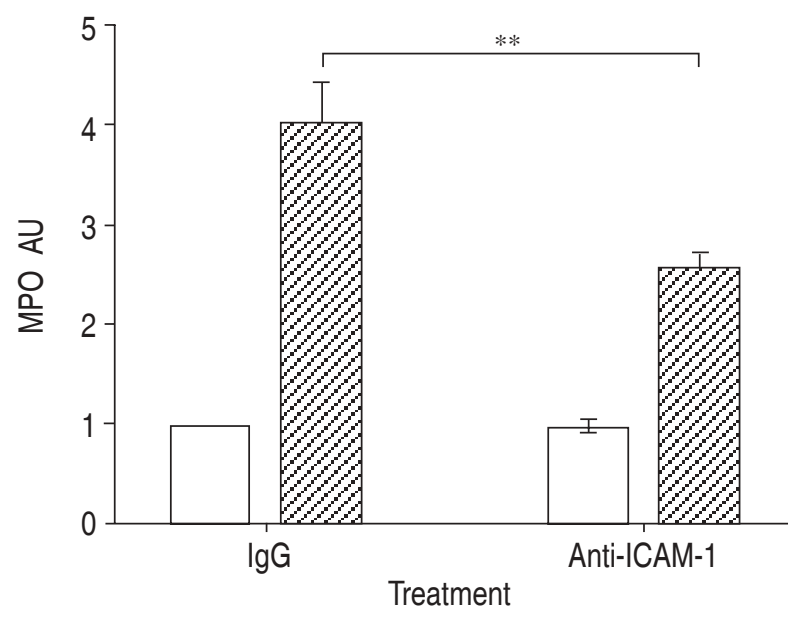

Fig. 8.-Neutrophil content of rat lung after intratracheal intercellular adhesion molecule-1 (ICAM-1) blockade in the lipopolysaccharide (LPS)-injured lung. Lungs were instilled with phosphate-buffered saline (PBS; $\square$ ) or LPS $(\mathbb{Z})$ in the presence of immunoglobulin-G (IgG) or anti-ICAM-1 $\left(200 \mu \mathrm{g} \cdot \mathrm{mL}^{-1}\right)$. The vascular system of the lungs was flushed $4 \mathrm{~h}$ later and the bronchoalveolar system lavaged. This was followed by determination of myeloperoxidase (MPO) levels, a measure of neutrophil content. Blocking airway ICAM-1 reduced MPO levels by $35 \%$. Data are expressed as mean \pm SEM $(n=5)$. AU: arbitrary units. **: $p<0.01$.

\section{Discussion}

Cytokines and LPS have been used extensively for stimulation of ICAM-1 expression on endothelial cells $[3,16,20,21]$. For the airway compartment, however, there is only limited information available concerning ICAM-1 upregulation and its possible biological function. As shown in previous studies, ICAM-1 is expressed on the bronchial epithelium (upper airways) and can also be induced there by instillation of LPS in vivo [16]. A functional role of ICAM-1 on bronchial cells in the pathogenesis of asthma has been suggested [22]. Although earlier studies demonstrated that ICAM-1 was not upregulated by cytokines or endotoxin on AECs in vitro [23], recent data have shown different results. FAKLER et al. [24] demonstrated clear upregulation of ICAM-1 on human AECs after LPS stimulation. On L2 cells, a line of rat AECs, increased ICAM-1 expression was seen exclusively on the apical part of the cell, assuming that interactions between neutrophils in the alveolar space and AECs were limited to this apical surface [13]. In addition, DENTENER et al. [25] described a human AEC line producing LPS-binding protein in response to interleukin-1 $\beta$ and $T N F-\alpha$. The results of this group also implicated these cells in the inflammatory processes. In the in vitro studies presented here, enhancement of ICAM-1 expression in AEC culture in response to stimulation was also observed.

The first part of the present study was undertaken to assess regulation of ICAM-1 on AECs after exposure to TNF- $\alpha$, IFN- $\gamma$ and LPS. The study clearly showed upregulation of ICAM-1 protein and ICAM-1 mRNA after stimulation with any of these three agonists. LPS was demonstrated to cause the strongest upregulation. A similar LPS-induced increase has previously been shown on alveolar macrophages [16, 18]. The macrophages, however, displayed a faster pattern of surface ICAM-1 upregulation than the AECs used in the present studies. This could be due to the fact that macrophages are the first cells interacting with a foreign substance in the airways. In addition to these in vitro results, the present data provide evidence that in vivo ICAM-1 expression on AECs can indeed be upregulated by exposure to LPS. Therefore, these studies provide strong evidence that epithelial upregulation of ICAM-1 occurs not only in bronchial cells (proximal airways) [16] but also on AECs (distal airways).

Compared to a line of AECs (L2 cells), ICAM-1 upregulation on AECs in primary culture revealed a similar expression pattern. With both cell types, a seven-fold increase in ICAM-1 mRNA levels was seen. However, baseline expression of ICAM-1 on L2 cells was significantly lower. This might be due to the fact that primary culture cells reflect type I rather than type II character. Type II staining of AEC primary cultures showed that the majority of the cells did not have type II character after 3 days in culture (data not shown).

The results of the adherence assays clearly demonstrate a functional role for ICAM-1 in the adhesion of neutrophils and macrophages to stimulated AECs. However, it appears that other adhesion molecules 
are also involved in this process, since only $\sim 40 \%$ of neutrophil adherence could be blocked by antiICAM-1. Adherence of neutrophils to LPS-stimulated AECs was much more robust than that of macrophages. In stimulated AECs, adhesion of neutrophils increased $114 \%$ as compared to macrophages, which increased $45 \%$. Increased adhesiveness between pneumocytes and neutrophils or macrophages in the setting of an inflammatory response would be expected to lead to intensified injury of the alveolar cell-lined barrier. The present in vitro studies with AECs incubated with PMA-stimulated neutrophils supported this. LPS-stimulated AECs showed enhanced cytotoxicity, implying that neutrophil adherence induces AEC killing. Although several recent studies have shown endothelial cell killing by neutrophils $[26,27]$, the present study suggests susceptibility of epithelial cells to injury related to AEC stimulation by LPS.

Airway instillation of antirat ICAM-1 demonstrated protective effects in the present studies. Similar results were seen with intravenous blockade of ICAM-1 in mice after intratracheal instillation of LPS [28]. A protective effect of intratracheally-applied anti-ICAM-1 was also found in an $\mathrm{IgG}$ immune complex-mediated lung injury [29]. In a model of Klebsiella pneumoniae-induced lung injury, however, epithelial blockade of ICAM-1 resulted in an impaired ability to clear $K$. pneumoniae from the lungs [30], implying that ICAM-1 also plays an important role in host defence. The present data are in contrast to these findings, for which there could be several reasons. One striking difference might be the severity of the injury. Although the $K$. pneumoniae-induced injury is described as causing mild inflammation, the endotoxin-induced injury is severe in terms of the inflammatory response. This is reflected by the cell count in BAL fluid being doubled in the bacteriallyinduced injury as opposed to the endotoxin evoking a 10-fold increase. Furthermore, O'BRIEN et al. [30] assessed the effect of anti-ICAM-1 after $24 \mathrm{~h}$, whereas the present studies were performed after $4 \mathrm{~h}$. Furthermore, upregulated ICAM-1 expression on different cell types (epithelial cells and macrophages) might not have the same effect in the inflammatory cascade. In addition, ICAM-1 might show pleiotropic effects depending on the time point of the response to injury. For instance, at an early time point after injury it might have pro-inflammatory character, whereas at a later time point, enhanced ICAM-1 expression might be protective. Blockade of ICAM-1 on alveolar macrophages could be excluded in the present study, as there was no increased ICAM-1 expression seen on macrophages after $4 \mathrm{~h}$ [16].

One interesting finding was the fact that ICAM-1 was not expressed on type II cells. The staining showed exclusively type I-located ICAM-1 expression. These data support previous in vitro results [23]. Type II cells have two functions: surfactant expression and conversion into type I cells. This mitotic and secretory activity might be one reason for the lack of immunoreactivity of these cells. Conversely, downregulation of the detected protein as a possible explanation for the absence of immunofluorescence staining cannot be fully excluded.

In conclusion, the present studies demonstrate that intercellular adhesion molecule-1 is upregulated on alveolar epithelial cells in vitro and in vivo following lipopolysaccharide stimulation. The increased expression of intercellular adhesion molecule-1 leads to enhanced adherence of neutrophils and macrophages, clearly demonstrating a biological function of intercellular adhesion molecule-1 on alveolar epithelial cells. Intercellular adhesion molecule-1-mediated neutrophil adherence to lipopolysaccharide-stimulated alveolar epithelial cells triggers alveolar epithelial cell injury with increased cytotoxicity. These studies indicate that the lower airway compartment plays an important role in endotoxin-induced inflammation. Again, these in vitro and in vivo studies may not fully reflect endotoxin-induced lung injury in patients. Further investigations providing clinical data will increase understanding of the corresponding clinical situation.

\footnotetext{
Acknowledgements. The authors wish to thank R. Kunkel and C. Gasser for development of illustrations and B. Schumann for assistance in the preparation of the manuscript. The authors also thank J. Biber for providing antitype IIb sodium phosphate cotransporter.
}

\section{References}

1. Mulligan MS, Smith CW, Anderson DC, et al. Role of leukocyte adhesion molecules in complement-induced lung injury. J Immunol 1993; 150: 2401-2406.

2. Mulligan MS, Varani J, Warren JS, et al. Roles of $\beta_{2}$ integrins of rat neutrophils in complement- and oxygen radical-mediated acute inflammatory injury. J Immunol 1992; 148: 1847-1857.

3. Mulligan MS, Vaporciyan AA, Miyasaka M, Tamatani $\mathrm{T}$, Ward PA. Tumor necrosis factor- $\alpha$ regulates in vivo intrapulmonary expression of ICAM-1. Am J Pathol 1993; 142: 1739-1749.

4. Bevilacqua MP. Endothelial-leukocyte adhesion molecules. Annu Rev Immunol 1993; 11: 767-804.

5. Albelda SM, Smith SW, Ward PA. Adhesion molecules and inflammatory injury. FASEB J 1994; 8: 504 512.

6. Sibille Y, Reynolds HY. Macrophages and polymorphonuclear neutrophils in lung defense and injury. Am Rev Respir Dis 1990; 141: 471-501.

7. Varani J, Dame MD, Gibbs DF, et al. Human umbilical vein endothelial cell killing by activated neutrophils. Lab Invest 1992; 66: 708-714.

8. Evans MJ, Cabral LJ, Stephens RJ, Freeman G. Transformation of alveolar type 2 cells to type 1 cells following exposure to $\mathrm{NO}_{2}$. Exp Mol Path 1975; 22: 142-150.

9. Simon RH, Paine R 3rd. Participation of pulmonary alveolar epithelial cells in lung inflammation. $J \mathrm{Lab}$ Clin Med 1995; 126: 108-118.

10. Shanley TP, Warner RL, Ward PA. The role of cytokines and adhesion molecules in the development of inflammatory injury. Mol Med Today 1995; 1: $40-45$. 
11. Cunningham AC, Milne DS, Wilkes J, Dark JH, Tetley TD, Kirby JA. Constitutive expression of MHC and adhesion molecules by alveolar epithelial cells (type II pneumocytes) isolated from human lung and comparison with immunocytochemical findings. J Cell Sci 1994; 107: 443-449.

12. Dobbs LG, Gonzalez R, Williams MC. An improved method for isolating type II cells in high yield and purity. Am Rev Respir Dis 1986; 134: 141-145.

13. Madjdpour C, Oertli B, Ziegler U, Bonvini JM, Pasch T, Beck-Schimmer B. Lipopolysaccharide induces functional ICAM-1 expression in rat alveolar epithelial cells in vitro. Am J Physiol 2000; 278: L572-L579.

14. Foreman KE, Vaporciyan AA, Bonish BK, et al. C5ainduced expression of $\mathrm{P}$-selectin in endothelial cells. $J$ Clin Invest 1994; 94: 1147-1155.

15. Ward PA, Duque RE, Sulavik MC, Johnson KJ. In vitro and in vivo stimulation of rat neutrophils and alveolar macrophages by immune complexes. Production of $\mathrm{O}_{2-}$ and $\mathrm{H}_{2} \mathrm{O}_{2}$. Am J Pathol 1983; 110: 297309.

16. Beck-Schimmer B, Schimmer RC, Warner RL, et al. Expression of lung vascular and airway ICAM-1 after exposure to bacterial lipopolysaccharide. Am J Respir Cell Mol Biol 1997; 17: 344-352.

17. Traebert M, Hattenhauer O, Murer H, Kaissling B, Biber J. Expression of type II Na-P(i) cotransporter in alveolar type II cells. Am J Physiol 1999; 277: L868L873.

18. Beck-Schimmer B, Schimmer RC, Schmal H, et al. Characterization of rat lung ICAM-1. Inflamm Res 1998; 47: 308-315.

19. Goldblum SE, Wu KM, Jay M. Lung myeloperoxidase as a measure of pulmonary leukostasis in rabbits. J Appl Physiol 1985; 59: 1978-1985.

20. Pober JS, Cotran RS. The role of endothelial cells in inflammation. Transplantation 1990; 50: 537-544.

21. Shen J, Ham RG, Karmiol S. Expression of adhesion molecules in cultured human pulmonary microvascular endothelial cells. Microvasc Res 1995; 50: 360-372.
22. Wegner CD, Gundel RH, Reilly P, Haynes N, Letts LG, Rothlein R. Intercellular adhesion molecule-1 (ICAM-1) in the pathogenesis of asthma. Science 1990; 247: 456-459.

23. Barton WW, Wilcoxen S, Christensen PJ, Paine R. Disparate cytokine regulation of ICAM-1 in rat alveolar epithelial cells and pulmonary endothelial cells in vitro. Am J Physiol 1995; 269: L127-L135.

24. Fakler CR, Wu B, McMicken HW, Geske RS, Welty SE. Molecular mechanisms of lipopolysaccharide induced ICAM-1 expression in A549 cells. Inflamm Res 2000; 49: 63-72.

25. Dentener MA, Vreugdenhil AC, Hoet PH, et al. Production of the acute-phase protein lipopolysaccharidebinding protein by respiratory type II epithelial cells: implications for local defense to bacterial endotoxins. Am J Respir Cell Mol Biol 2000; 23: 146-153.

26. Varani J, Fligiel SEG, Till GO, Kunkel RG, Ryan US, Ward PA. Pulmonary endothelial cell killing by human neutrophils. Lab Invest 1985; 53: 656663.

27. Murphy HS, Warner RL, Bakopoulos N, Dame MK, Varani J, Ward PA. Endothelial cell determinants of susceptibility to neutrophil-mediated killing. Shock 1999; 12: 111-117.

28. Kumasaka T, Quinlan WM, Doyle NA, et al. Role of the intercellular adhesion molecule-1 (ICAM-1) in endotoxin-induced penumonia evaluated using ICAM-1 antisense oligonucleotides, anti-ICAM-1 monoclonal antibodies and ICAM-1 mutant mice. J Clin Invest 1996; 97: 2362-2369.

29. Mulligan MS, Vaporciyan AA, Warner RL, et al. Compartmentalized role for leukocytic adhesion molecules in lung inflammatory injury. $J$ Immunol 1995; 154: 1350-1363.

30. O'Brien AD, Standiford TJ, Bucknell KA, Wilcoxen SE, Paine $\mathrm{R}$ 3rd. Role of alveolar epithelial cell intercellular adhesion molecule-1 in host defense against Klebsiella pneumoniae. Am J Physiol 1999; 276: L961-L970. 